\title{
User Experience: Impact Occupational Factors on Safety and Health Through Ergonomic Approach among Older Taxi Drivers Community in Malaysia
}

Irwan Syah Md Yusoff, Muhammad Heikal Ismail \& Elistina Abu Bakar

To Link this Article: http://dx.doi.org/10.6007/IJARBSS/v11-i11/11604

DOI:10.6007/IJARBSS/v11-i11/11604

Received: 20 September 2021, Revised: 21 October 2021, Accepted: 30 October 2021

Published Online: 15 November 2021

In-Text Citation: (Yusoff et al., 2021)

To Cite this Article: Yusoff, I. S. M., Ismail, M. H., \& Bakar, E. A. (2021). User Experience: Impact Occupational Factors on Safety and Health Through Ergonomic Approach among Older Taxi Drivers Community in Malaysia. International Journal of Academic Research in Business and Social Sciences, 11(11), 1245-1257.

Copyright: (c) 2021 The Author(s)

Published by Human Resource Management Academic Research Society (www.hrmars.com) This article is published under the Creative Commons Attribution (CC BY 4.0) license. Anyone may reproduce, distribute, translate and create derivative works of this article (for both commercial and non-commercial purposes), subject to full attribution to the original publication and authors. The full terms of this license may be seen at: http://creativecommons.org/licences/by/4.0/legalcode

Vol. 11, No. 11, 2021, Pg. $1245-1257$

Full Terms \& Conditions of access and use can be found at http://hrmars.com/index.php/pages/detail/publication-ethics 


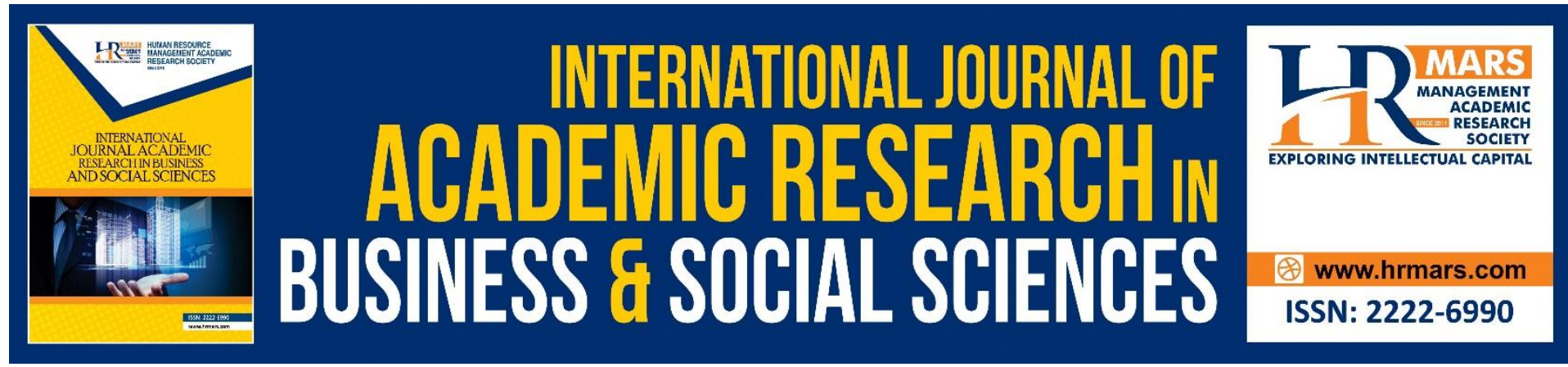

\title{
User Experience: Impact Occupational Factors on Safety and Health Through Ergonomic Approach among Older Taxi Drivers Community in Malaysia
}

\author{
Irwan Syah Md Yusoff ${ }^{1,2}$, Muhammad Heikal Ismail ${ }^{3}$ \& Elistina \\ Abu Bakar ${ }^{4}$ \\ ${ }^{1}$ Department of Resource Management and Consumer Studies, Faculty of Human Ecology, \\ Universiti Putra Malaysia, Serdang, 40300, MALAYSIA, ${ }^{2}$ Malaysian Research Institute on \\ Ageing Universiti Putra Malaysia, Serdang, 40300, MALAYSIA, ${ }^{3}$ Department of Chemical and \\ Environmental Engineering, Faculty of Engineering, Universiti Putra Malaysia, Serdang, \\ 40300, Malaysia, ${ }^{4}$ Department of Resource Management and Consumer Studies, Faculty of \\ Human Ecology, Universiti Putra Malaysia, Serdang, 40300, MALAYSIA \\ Email correspondence: irwansyah@upm.edu.my
}

\begin{abstract}
Background: One of the alternative professions that may include the older community is taxi drivers. Subsequently, they have to take explicit thought during driving activities as indicated by their capacity and ability to sustain their lives while minimizing health problems and increasing safety. Therefore, this paper aimed to study from a user experience the impact occupational factors on safety and health by an ergonomic approach among older community taxi drivers in Malaysian. Methods: A cross-sectional study was led utilizing a selfadministered survey instrument. Purposive method sampling used based on inclusive criteria; age 60 years old and above, self-driving taxi more than one year, no disabilities and registered with Ministry of Transport (MOT). A total of 443 respondents participated in the study. SPSS software version 20.0 to analyse the data. Results: More than half of the respondents $(70.0 \%)$ felt back pain in the past 12 months, and $75.4 \%$ in the last seven days. There is a significant relationship health problem ( $p<0.05$ ) between variables; BMI, smoking status, carrying luggage into the trunk, supporting of the backrest for the whole body, the effect of the seat size on comfortable driving, feeling of back pain is mainly due to the seat design and longdistance driving and driving posture analysis at the high-risk position and awkward body posture on seat design during handling task. Conclusion: The low implication awareness on ergonomics education could increase health problem and decrease safety while handling the task among older taxi driver's community in Malaysia.
\end{abstract}

Keywords: Older, Taxi Drivers, Safety and Health, Ergonomic, Malaysia

\section{Introduction}

Malaysia is experiencing challenges in changing the demographic profile of the population. Department of Social Welfare Malaysia (DSWM) described that the people aged 60 years and above fall into a category of elderly as referred to the "World Assembly on Aging, 1982" in 
Vienna. Based on statistics from the Department of Statistics Malaysia (DOSM, 2016) shows the population aged 65 years and above increased by 0.2 per cent from 5.8 per cent in 2015 to 6.0 per cent and equivalent to 1.9 million population aged in Malaysia in 2016, and this number will continue to increase from year to year. The older population has increased dramatically compared to other age groups making it one of the indicators for a developed country. Malaysia is experiencing challenges to changing the demographic profile of the population and heading towards an older country. Therefore, based on these statistics, it is possible to expect the older community to continue employment even after retirement; their past environment influences this.

Therefore, the older community require an explicit thought to sustain their life according to their capability and ability in this challenging world. Older characteristics may differ from other ages in terms of physiological, perceptual, sensory, cognitive, and motor capacities that may affect how the older people work together with tasks and behaviours (Herriotts, 2005). The limited ability among the older could affect their lifestyle, health and also driving behaviour. Therefore, an older community may continue to serve their services to other jobs after retirement or looking for manageable works according to their ability or do a part-time job to support family economic-financial and sustain life in the challenging world. These communities prefer to be taxi drivers to replace previous jobs after retirement. The job is considered a light job that is easy to handle, less energy, low cost, no specific requirement (standard licensed), no specific regulation, and it is an advantage if they have experience in driving in a commercial or private car. According to data in 2016 from Land Public Transport Commission (LPTC), approximately 64,547 registered taxi drivers in Malaysia. These numbers are also representing taxi drivers under the older community category.

According to the annual statistical report 2007-2010 (MIROS, 2012), more than $80 \%$ of accidents involved in passenger cars are fatal crashes. Consequently, the characteristics of older taxi drivers are so vital to comprehend, and therefore, the ageing process makes old individuals increasingly susceptible to injuries. Furthermore, the body structure of older people is too fragile when compared to other adults. Because their body repairing mechanism receives less energy to repair damaged and disrupted tissues, and their skeletal system is more pruned to damage through bone loss.

Employment as a taxi driver is a high risk that can lead to fatalities due to inter-motor vehicle accidents (Mayhew et al., 2000; Goetsch, 2010) with 14.9 taxi driver deaths than the 3.3 ratio for 100,000 other jobs. The employment of taxi drivers can be described by the low, dangerous, uneconomical pay for work and lower-class employment. The average working time of taxi drivers is 10.5 hours per day for 6.4 days in a week, and on average, this group allocates 3.5 hours of waiting time to get passengers for each day (Yang et al., 2014; ISM et al., 2020; AZA et al. al., 2018; ISMY et al., 2020; ISM et al., 2017). From previous studies, fatigue factors have always been associated with long driving periods. Long-term driving results in fatigue and can affect driving performance, and it is classified as physical and mental fatigue (ISM et al., 2020; AZA et al., 2018; ISMY et al., 2020; ISM et al., 2017;). Driving for an extended time causes fatigue and can affect driving performance, and it is classified as physical and mental fatigue. The measurement tool introduced by Hermanns et al (2008); ISM et al (2020) also showed that awkward posture and exposure to high vibration when driving at high risk might lead to musculoskeletal disorders (MSDs). In other words, the leading cause of physical fatigue is due to driving posture (Hirao et al., 2006).

Some aspects make older drivers distinct from other workers regarding exposure expectations when dealing with MSD-related jobs. As shown by Yang et al. (2014), their 
average working time is 10.5 hours a day, 6.4 days a week, and an average of 3.5 hours a day for passengers (Yang et al., 2014). A few other scientists, such as AZA et al., 2018; ISMY et al., 2020; Chen et al., 2005; Funakosh et al., 2004 and Tamrin et al., 2007, have found that other occupational factors, such as whole-body vibration, limited driving space, long working hours, long-distance driving, total mileage, taxi driver time, monotonous driving, work stress, and job dissatisfaction, that contribute to low back injuries (AZA et al., 2018; ISMY et al., 2020; ISM et al., 2020; Funakosh et al., 2004; Tamrin et al., 2007). From past literature, fatigue is continuously related to a long driving time and can be directly influenced by the driver's performance. Therefore, this is further classified into two: physical and emotional exhaustion. Taxi drivers are at high risk of disrupting the human biological clock rhythm and risk of stress, exhaustion, insomnia, anxiety, etc (Yang et al., 2014).

The application of ergonomics, for example, safety and health for older taxi drivers, is essential for a better working way of life and minimizing medical problems on work-related MSDs. Furthermore, it increases the health level and safety among older taxi drivers. Therefore, the principal objective of this study is to assess the impact of occupational factors on safety and health from an ergonomic approach of the older Malaysian taxi community from their experience. According to the authors' best knowledge, this is the first study that applies an ergonomic approach was made in the context of Malaysia to assess this problem.

\section{Materials and Methods}

The cross-sectional study was done utilizing a self-administered questionnaire to investigate the characteristics of background details among older taxi drivers in Peninsular Malaysia. The survey was managed around both the rural and urban areas in four regions of Malaysia. The purposive sampling technique was chosen, and 443 respondents participated in the survey. The primary inclusion criteria that have to select the samples; above 60 years of age, having a minimum of 1-year experience in taxi driving, and having SPAD registration. However, drivers who have had a history of major surgery or a history of neurological problems which have already attended any course or training related to occupational health and part-time drivers who work less than 4 hours a day have been excluded. The "Budget Car" and "Hired Car" taxi drivers were only selected for the study and characteristics of the car itself. The car seats should be in standard seat design, and no modification was involved. Each survey took approximately 10-15 minutes to complete. The respondents kindly asked to obtain a small token of appreciation if they successfully took part in the survey. Complete information related to their experience; work characteristics, some health issues, and details of the driving posture were collected.

The face-to-face interviews were conducted with the older taxi drivers to obtain fully completed questionnaires and minimize the misinterpreted responses. The questionnaire consisted of two sections. The initial part of the questionnaire was on socio-demographic characteristics and the past medical history of the respondent. The second part of the questionnaire was on the background of user experience such as total number of picking up passengers per day, working hours per day, period of resting time per day, type of employment, number of years working as a taxi driver, total driving distance per-week, the regular starting time of driving, competency and confident level of driving, feelings about the back pain within past seven days as well as last 12 months and type of activities doing in the leisure time.

The interviews were conducted at the public area, bus stations, railway stations, taxi stations, shopping malls, business zones, rural and urban hotspot areas, etc. According to 
statistics available in 2016, the most highly registered taxi types were budget taxi services (61.2 percent) and hired car services ( 26.6 percent) with SPAD compared to other services (Table 1). Other than that, these taxi types are listed as one of the cheap taxi types with standard/regular car seat designs compared to the various types of taxi services, as defined in the specification. Data analysis was conducted using version 20 of the SPSS program. Descriptive statistics were collected for all variables in the analysis, and the binary logistic regression technique was used to determine the relationship between occupational performance with health and safety among older taxi drivers.

Table 1: Number of licenses and break down of the taxi services based on their type

\begin{tabular}{lll}
\hline Taxi services & Number of licenses & Percentage (\%) \\
\hline Budget & $\mathbf{3 9 , 5 0 5}$ & $\mathbf{6 1 . 2}$ \\
\hline Airport & 3,135 & 5.0 \\
Premier & 376 & 0.6 \\
\hline Hired Car & $\mathbf{1 7 , 2 2 4}$ & $\mathbf{2 6 . 6}$ \\
\hline TEKS1M & 935 & 1.4 \\
Executive & 3,372 & 5.2 \\
Total & 64,547 & 100 \\
\hline
\end{tabular}

Source: ISMY et al., 2020

\section{Result}

\section{Socio- demographic details of the older taxi drivers}

The majority (57.6\%) of older drivers used 'budget' as a type of taxi. Almost all respondents were male $(98.9 \%)$. The mean $( \pm S D)$ age of the respondents was $66.0 \pm 3.8$ years, and age ranged from 60 to 83 years old. Most older taxi drivers were aged more than 66 years old (50.3\%). BMI was overweight (48.5\%), and the majority was Malay (68.6\%); the second was India (17.8\%), secondary school (59.1\%) for education level. The majority $(66.4 \%)$ of respondents worked under the company. Mean income per month RM 2000 \pm 796.8 from RM200 to RM6000.The smoking status answers smoker (yes) more than half (66.1\%). The details of background older taxi drivers are shown in Table 2. 
Table 2: Background older taxi drivers

\begin{tabular}{lllll}
\hline Factors & $\mathbf{N}(\%)$ & Mean \pm (SD) & Min & Max \\
\hline Category taxi & & & \\
Hired car & $188(42.4)$ & & \\
Budget & $255(57.6)$ & & \\
\hline Gender & & & \\
Male & $438(98.9)$ & & \\
female & $5(1.1)$ & & \\
\hline Age & & $66 \pm 3.8$ & \\
$60>65$ & $220(49.7)$ & & \\
$>66$ & $223(50.3)$ & & \\
\hline BMI & & & \\
Underweight & $6(1.4)$ & & \\
Normal & $137(30.9)$ & & \\
Overweight & $215(48.5)$ & & \\
Obese & $85(19.2)$ & & \\
\hline Ethnicity & & & \\
Malay & $304(68.6)$ & & \\
India & $79(17.8)$ & & \\
Chinese & $59(13.3)$ & & \\
\hline Education & $18(4.1)$ & & \\
None & $161(36.3)$ & & \\
Primary school & $262(59.1)$ & & \\
Secondary school & $2(0.2)$ & & \\
University & & & \\
\hline Jobs sectors & $294(66.4)$ & & \\
Company & $149(33.6)$ & & \\
Self - employed & & & \\
\hline Income per-mont.(RM) & & & \\
\hline Smoking status & & & \\
Yes/frequent & & & \\
No/never & & & \\
\hline 443 & & & \\
\hline
\end{tabular}

Abbreviations and Notes: $\mathrm{SD}=$ Standard deviation, Min. = Minimum, Max. $=$ Maximum

\section{Characteristics of the Older Taxi Drivers}

According to the results given in Table 3, taxi model Iswara model is the highest (52.8\%), Saga model is the second highest (21.9\%), followed by Wira model (17.8\%) and Waja model (7.4\%). The majority (93.3\%) respondents of the older taxi drivers' average number of passengers obtain per-day was $6-10$ times, and half $(53.0 \%)$ of them were never taken a rest per week. Most of them (91.6\%) were driven more than 8 hours per-day and average of 56 hours perweek. Moreover, $57.6 \%$ of the elderly taxi drivers do not prefer to have a sleep/nap during their waiting time. About $45.4 \%$ was waiting $2-3$ hours and $24.8 \%$ of the respondents should be waited more than four hours per-day to obtain a customer. Around $91.4 \%$ of the drivers were driven more than $250 \mathrm{~km}$ per-week. Furthermore, less than half $(38.1 \%)$ of the 
respondents were not driving the taxi until mid-night. However, only $23.9 \%$ always stays until mind-night. Most of the elderly taxi drivers prefer morning time (56.4\%) to begin the driving of their taxi and $82.1 \%$ was confident with the level of their driving skills. More than $70.0 \%$ were complained that they were having back pain within most recent 12 -month period and furthermore, $75.4 \%$ stated that the feeling of the back pain in the previous 7 days. About $94.8 \%$ of the elderly taxi drivers believed that feeling back pain is majorly due to their work environment. Meanwhile, vast majority of them (98.2\%) consistently convey travelers' luggage into the trunk, and nearly fifty percent (48.1\%) of them have carried luggage that was weighted more than $11 \mathrm{~kg}$. Moreover, their total highest driving experience as taxi drivers was ranged within $6-15$ years, and the percentage was $43.3 \%$. Respondents using Iswara model are the highest (52.8\%), Saga model is the second-highest (21.9\%), followed by Wira model (17.8\%) and Waja model (7.4\%).

Tables 3: Characteristics of the elderly taxi drivers

\begin{tabular}{lc}
\hline Factors & $\mathbf{N}(\%)$ \\
\hline Taxi Model & $234(52.8)$ \\
Iswara & $97(21.9)$ \\
Saga & $33(7.4)$ \\
Waja & $79(17.8)$ \\
Wira & \\
\hline Number of passengers obtain per-day & $412(93.3)$ \\
6-10times & $30(6.7)$ \\
$>11$ times & \\
\hline Rest taken per-week & $208(47.0)$ \\
Yes & $235(53.0)$ \\
No & \\
\hline Total hours of driving per-day & $37(8.4)$ \\
1>7hours & $406(91.6)$ \\
$>8$ hours & \\
\hline Average hours of driving per-week & $28(6.3)$ \\
$48-56$ hours & $415(93.6)$ \\
$>56$ hours & \\
\hline Having a sleep/nap till waiting the passenger & $188(42.4)$ \\
Yes & $255(57.6)$ \\
\hline No & \\
\hline Waiting hours per-day for passengers & $132(29.8)$ \\
$<1$ hours & $201(45.4)$ \\
2>3hours & $110(24.8)$ \\
\hline Ahours & \\
51>150km & $1(0.2)$ \\
>250km & $37(8.4)$ \\
\hline Possibility of driving until mid-night & $405(91.4)$ \\
Always & $106(23.9)$ \\
Not frequent & $168(37.9)$ \\
\hline
\end{tabular}




\begin{tabular}{lc} 
Never & $169(38.1)$ \\
\hline Driving time & $250(56.4)$ \\
Morning & $142(32.1)$ \\
Afternoon & $27(6.1)$ \\
Evening/night & $24(5.4)$ \\
Anytime & \\
\hline Confident level of driving skills & $79(17.8)$ \\
Average & $364(82.1)$ \\
Confident & \\
\hline Feeling of back pain in last 12-month period & $310(70.0)$ \\
Yes & $133(30.3)$ \\
No & \\
\hline Feeling of back pain in last 7 days & $334(75.4)$ \\
Yes & $109(24.6)$ \\
No & \\
\hline Cause of the back pain due to the job & $420(94.8)$ \\
Yes & $23(5.2)$ \\
No & \\
\hline Carrying luggage into the hood & $435(98.2)$ \\
Yes & $8(1.8)$ \\
No & \\
\hline Loading of luggage weight & $42(9.5)$ \\
$1>5 \mathrm{~kg}$ & $180(40.6)$ \\
$6>10 \mathrm{~kg}$ & $213(48.1)$ \\
$>11 \mathrm{~kg}$ & $8(1.8)$ \\
\hline Never & \\
\hline Total years of experience in driving & $160(36.1)$ \\
$1>5$ yrs & $192(43.3)$ \\
$>16 y \mathrm{yrs}$ & $91(20.5)$ \\
\hline $\mathrm{N}=443$ & \\
\hline & \\
\hline
\end{tabular}

\section{Risk Factors of the Older Taxi Drivers}

The results of Table 4 show that the result analysis risk factors which have a relationship with health problems on work MSDs at upper torso body parts of the older taxi drivers. The result showed a significant relationship $(<0.05)$ contributing to risk to develop MSDs; BMI underweight \& obese (Od ratio: 4.93, Cl: 1.57,15.53, P: 0.00), smoking experience - Yes (Od ratio: $2.33, \mathrm{Cl}: 1.09,4.97, \mathrm{P}: 0.03$ ), lifting passenger goods- Yes (Od ratio: $16.51, \mathrm{Cl}$ : $2.58,105.85, \mathrm{P}: 0.00$ ), seat backrest supports entire back body.- No (Od ratio: $3.27, \mathrm{Cl}$ : 1.27,8.34 , P: 0.01) and posture analysis (RULA) - action scores 3 \& 4 (Od ratio: 8.72, $\mathrm{Cl}$ : $0.97,78.34, \mathrm{P}:$ 0.05). However, there was an increase in risk factors but no significant relationship factors for seat size affecting driving comfort - Yes (Od ratio: 1.49, $\mathrm{Cl}$ : 0.32, 7.02, P: 0.61) and back pain problems caused by seat design sitting and long driving - Yes (Od ratio: $1.07, \mathrm{Cl}: 0.13,8.68, \mathrm{P}: 0.95)$. 
Tables 4: Risk factors for work MSDs at upper torso body parts

\begin{tabular}{|c|c|c|c|}
\hline Variables & Ratio (Od) & $95 \%$ (C.I) & $P$ value \\
\hline \multicolumn{4}{|l|}{ BMI } \\
\hline Normal & 1.00 & & \\
\hline underweight \& obsess & 4.93 & $(1.57,15.53)$ & $0.00 * *$ \\
\hline \multicolumn{4}{|l|}{ Smoking Experience } \\
\hline No & 1.00 & & \\
\hline Yes & 2.33 & $(1.09,4.97)$ & $0.03 * *$ \\
\hline \multicolumn{4}{|l|}{ Lifting Passenger Goods } \\
\hline No & 1.00 & & \\
\hline Yes & 16.51 & $(2.58,105.85)$ & $0.00 * *$ \\
\hline \multicolumn{4}{|c|}{ Seat Backrest Supports Entire Back Body } \\
\hline Yes & 1.00 & & \\
\hline No & 3.27 & $(1.27,8.34)$ & $0.01 * *$ \\
\hline \multicolumn{4}{|c|}{ Score Action analysis Posture (RULA) } \\
\hline $1>2$ & 1.00 & & \\
\hline $3>4$ & 8.72 & $(0.97,78.34)$ & $0.05 * *$ \\
\hline \multicolumn{4}{|c|}{ Seat Size Affecting Driving Comfort } \\
\hline No & 1.00 & & \\
\hline Yes & 1.49 & $(0.32,7.02)$ & 0.61 \\
\hline \multicolumn{4}{|c|}{ Back Pain Problems Caused by Seat Design Sitting and } \\
\hline \multicolumn{4}{|l|}{ Long Driving } \\
\hline No & 1.00 & & \\
\hline Yes & 1.07 & $(0.13,8.68)$ & 0.95 \\
\hline
\end{tabular}

$\mathrm{N}=443 .{ }^{* *}$ Significant $p<0.05$

Abbreviations and Notes: $\mathrm{Cl}=$ Confident Interval, Od. $=$ odds

\section{Discussion}

The first national car (Proton) model used for taxi services widely in Malaysia is the first edition of the Proton Iswara model in the 1990s and 2000s. Thus, the study showed that $52.8 \%$ of respondents had chosen the Proton Saga Iswara model and $21.9 \%$ for the second edition of Proton Saga. This model has high demand among older taxi drivers because the selling price in the market is lower than other Proton model variations, easy to maintain, more economical, and same supplier seats for all economic variation of Proton models. Overall, the highest prevalence of MSDs occurring in the last 7 days of driving was in the back, and lower limbs, namely left and right hips (93.6\%; 92.1\%), right and left buttocks (92.0\%; 91.0\%), lower back $(87.4 \%)$, middle back $(81.7 \%)$ and upper back $(74.7 \%)$ ) as well as neck $(53.0 \%)$. On the other hand, based on a study conducted by Ahmad et al. (2017) taxi drivers in Jeddah were found to contradict the results of a study of limb MSDs in the last 7 days of driving: lower back and knees (29.4\%), neck (27.4\%), upper back (23.5\%) and shoulders (20.0\%). However, there is almost a similarity of GRO prevalence of the last 7 days of driving with the results of studies on the middle back limb (79.0\%) and upper back of the body $(65.0 \%)$ that have been conducted by Srivastava and Kiran (2014). Overall, a total of $92.3 \%$ of older taxi drivers' complaints agreed that all MSDs problems occurred in the last 12 months and the last 7 days of driving on the limbs were due to seat design and driving posture. Previous researchers have also agreed that vehicle seat design affects driving performance and influences the comfort 
and physical health condition of the driver himself (AZA et al., 2018; ISMY et al., 2020; ISM et al., 2020; Farzana, 2006).

The results have been shown that there is no significant difference between the respondents' age groups which are 60-65 years of age and above 66 years old. As per Pruesser et al (1998), the drivers whose age is within the range of 65 - 69 years are 2.26 times higher at risk to meet a fatal multi-vehicle crash contrasted with the drivers whose age is within the range of 40- 49 years (Pruesser et al., 1998). About, 66.4\% older taxi drivers in Malaysia work under a company to make assurance of their life and family well-being and similar results were recorded previously in the study of Onawumi and Lucas (2012) in Nigeria (Onawumi et al., 2012). According to them, $85 \%$ of taxi drivers in Nigeria were employed under taxi company as drivers as means of living. The average income per month for an older taxi driver in Malaysia were RM 2000.00 and similar results were stated by AL- Dubai et al (2012) in their research on "Prevalence and determinants of low back pain among taxi drivers in Malaysia" (AL-Dubai et al., 2012).

Further, according to the previous research, spending more time to pick-up and waiting for passengers every day or per-week lead to low back pain injury (Miyamoto et al., 2008). Tamrin et al (2007) revealed that the monotones in long-distance driving affected the factors like, low back pain and other injuries that are related to MSDs (Tamrin et al., 2007). Along with that the results of the current study were shown that $91.4 \%$ of the older taxi drivers who drive more than $250 \mathrm{~km}$ per week has been potentially led to develop the body muscle problems. Furthermore, the study found that having back pain in the past 12 months among taxi drivers in Malaysia was $70.0 \%$ and having back pain in the past seven days was $75.4 \%$. Similar trend of results was also found in previous research which was conducted in Taiwan and Japan and according to them, the predominance of lower back pain in past 12 months and past seven days among taxi drivers were $45.8 \%$ and $51 \%$ respectively (Chen et al., 2005; Funakosh et al., 2004).

The results showed a significant association between MSDs in the upper limbs and low back with $\mathrm{BMI}$ - underweight and obese (Od ratio: 4.93, $\mathrm{Cl}: 1.57,15.53, \mathrm{P}: 0.00$ ). Previous studies conducted among taxi drivers in Iran who worked for more than 4 years found that obesity, gastrointestinal diseases, fatigue, MSDs, sensory complaints, including hemorrhoids, were higher than other populations (Nasri and Moazenzadeh, 2006). This statement is based on reports from taxi drivers stating that they eat junk food that they easily get on the road while driving (Ramukumba and Mathikhi, 2016). This attitude is an unhealthy dietary imbalance or poor eating behavior. Obese taxi drivers are prone to cardiovascular disease, hypertension, stage 2 diabetes, and other diseases (Bray et al., 2009). It can be concluded that obesity is one of the risk factors that carry various diseases such as stroke, cardiovascular disease, hypertension and diabetes, as well as causing problems to arthritis and MSDs (Yesurajan and Indra, 2017). According to Yesurajan and Indra (2017), smoking can increase the risk of cardiovascular disease. This factor causes about $30 \%$ of all deaths due to cancer and the leading cause of chronic lung disease. The results on the seat support variable supporting the entire back of the body - No (Od ratio: 3.27, $\mathrm{Cl}: 1.27,8.34, \mathrm{p}: 0.01$ ) showed a significant association with MSDs problems on the upper limbs and lower back. Thus, there are similarities with the study's statement that uncomfortable chairs and uncomfortable backrest support are the causes of pain in lower back pain (Kresal et al., 2017). Seating comfort is also closely linked to the driver's seat. Although there is an interaction between the driver and the vehicle seat, Gyi (2013) has identified when the backrest supports the back body. The pelvic bones will naturally twist until the backrest fully supports the body. 
Accordingly, the study results on the seat support variable keeping the entire back of the body - No (Od ratio: $3.27, \mathrm{Cl}: 1.27,8.34$, p: 0.01 ) showed a significant association with MSDs problems in the upper limbs and lower back. Comfort in the car driver's seat had a substantial relationship with features on the driver support seat posture (AZA et al., 2018; ISMY et al., 2020; ISM et al. 2020). There was a significant association between MSDs in the upper limbs and lower back on RULA posture analysis with analytical action level scores of $3 \& 4$ (Od ratio: $8.72, \mathrm{Cl}: 0.97,78.34, \mathrm{p} 0.05)$. This is due to several things including the state of static posture when driving for a long time. There are previous studies confirm that posture in a long sitting position while driving has a cumulative effect of fatigue on the back muscles of the body and causes muscle tension in the spine leading to low back pain problems (Vandergrift et al., 2012; Coenen et al., 2014; ISMY et al., 2020; ISM et al., 2020).

\section{Conclusion}

In conclusion, this study gives a concrete base on the characteristics among old taxi drivers, especially recognizing relationships and risk factors essential to cause health problems due to occupational driving carrier in taxi among older community ini Malaysia. It also helps us initiate the prevention of MSDs in terms of health and identify risk factors within the cycle of economic challenges. Therefore, more investigation is expected to explore this topic that will benefit older taxi drivers to enhance their health and improve quality of life, especially their safety during their job.

\section{Ethical Considerations}

All ethical considerations, such as plagiarism, informed consent, misconduct, data fabrication and/or falsification, double publication and/or submission, and redundancy, have been observed diligently by the authors.

\section{Acknowledgments}

No financial support.

\section{References}

AL-Dubai, S. A. R., Qureshi, A. M., Ismail, N. H., \& Rampal, K. G. (2012). Prevalence and determinants of low back pain among taxi drivers in Malaysia. A cross sectional study. Journal of Advanced Medical Research, 2(4), 129-43.

Bovenzi, M., \& Zadini, A. (1992). Self-reported low back symptoms in urban bus drivers exposed to whole-body vibration. Spine, 17(9), 1048-1059.

Chen, J. C., Chang, W. R., Chang, W., \& Christiani, D. (2005). Occupational factors associated with low back pain in urban taxi drivers. Occupational Medicine, 55(7), 535-540.

Dalziel, J. R., \& Job, R. S. (1997). Motor vehicle accidents, fatigue and optimism bias in taxi drivers. Accid Anal Prev, 29(4), 489-94.

Dunk, N. M., \& Callaghan, J. P. (2005). Gender-based differences in postural responses to seated exposures. Clin Biomech, 20(10), 1101-10.

Ebe, K., \& Griffin, M. J. (2001). Factors affecting static seat cushion comfort. Ergonomics, 44 (10), 901-21.

Figà-Talamanca, I., Cini, C., \& Varricchio, G. C. (1996). Effects of prolonged auto vehicle driving on male reproductive function: a study among taxi drivers. Am J Ind Med, 30(6): 750-58. 
Funakoshi, M., Taoda, K., \& Tsujimura, H. (2004). Measurement of whole-body vibration in taxi drivers. J Occup Health, 46(2), 119-24.

Herriotts, P. (2005). Identification of vehicle design requirements for older drivers. Appl Ergon, 36(3), 255-62.

Hulshof, C. T., Verbeek, J. H., \& Braam, I. T. (2006). Evaluation of an occupational health intervention programme on whole-body vibration in forklift truck drivers: a controlled trial. Occup Environ Med, 63(7), 461-68.

Magnusson, M. L., Pope, M. H., \& Wilder, D. G. (1996). Are occupational drivers at an increased risk for developing musculoskeletal disorders? Spine, 21(6), 710-17.

Majid, A. Z. A., Yusoff, I. S. M., \& Tamrin, S. B. M. (2018). Assessment on sitting posture relation to risk factors by using Chi-Square test among elderly taxi drivers in peninsular Malaysia. Planning Malaysia, 16(6).

MIROS (2012). https://www.miros.gov.my/1/publications.php?id_page=19.

Miyamoto, M., Konno, S., \& Gembun, Y. (2008). Epidemiological study of low back pain and occupational risk factors among taxi drivers. Ind Health, 46(2), 112-17.

Mohamad, D., Deros, B. M., \& Daruis, D.D. (2016). Comfortable driver's car seat dimensions based on Malaysian anthropometrics data. Iran J Public Health, 45(1), 106-13.

Onawumi, A. S., \& Lucas, E. B. (2012). Ergonomic investigation of occupational drivers and seat design of taxicabs in Nigeria. ARPN J Sci Technol, 2(3), 214-20.

Preusser, D. F., Williams, A. F., \& Ferguson, S. A. (1998). Fatal crash risk for older drivers at intersections. Accid Anal Prev, 30(2), 151-59.

Raanaas, R. K., \& Anderson, D. (2008). A questionnaire survey of Norwegian taxi drivers' musculoskeletal health, and work-related risk factors. Int J Ind Ergon, 38(3), 280-90.

Schneider, L. W. (1989). Survey of driver seating discomfort and related factors. https:// deepblue.lib.umich.edu/bitstream/handle/2027.42/843/78572.0001.001.pdf?sequen $\mathrm{ce}=2$

Smith, D., Meshkati, N., \& Robertson, M. (1993). Automotive ergonomics: The older driver and passenger. Publication of Taylor and Francis Itd.

Tamrin, S. B. M., Yokoyama, K., \& Jalaludin (2007). The association between risk factors and low back pain among commercial vehicle drivers in peninsular Malaysia: a preliminary result. Ind Health, 45(2), 268-78.

Van Solinge, H., \& Henkens, K. (2008). Adjustment to and satisfaction with retirement: Two of a kind? Psychol Aging, 23, 422-34.

Vink, P., \& Hallbeck, S. (2012). Editorial: Comfort and discomfort studies demonstrate the need for a new model. Appl Ergon, 43(2), 271-76.

Wang, M. (2007). Profiling retirees in the retirement transition and adjustment process: examining the longitudinal change patterns of retirees' psychological well-being. J Appl Psychol, 92(2), 455.

Welch, L., Haile, E., \& Boden, L. I. (2009). Musculoskeletal disorders among construction roofers-physical function and disability. Scand J Work Env Hea, 56-63.

Yang, Y., Fan, X. S., \& Tian, C. H. (2014). Health status, intention to seek health examination, and participation in health education among taxi drivers in Jinan, china. Iran Red Crescent Med J, 16(4), 1-6.

Yasobant, S., Chandran, M., \& Reddy, E.M. (2015). Are bus drivers at an increased risk for developing musculoskeletal disorders: An ergonomic risk assessment study. J Ergonom, 1-5. 
Yusoffa, I. S. M., Majida, A. Z. A., \& Tamrin, S. B. M. (2017, November). Ergonomic perspective: driving awkward body posture cause health problem among older taxi driver's in Malaysia. Social Sciences Postgraduate International Seminar (SSPIS) 2017.

Yusoff, I. S. M., Tamrin, S. B. M., \& Majid, A. Z. A. (2020, December). Elderly taxi drivers: evaluation of driving posture in malaysia using rapid upper limb assessment (RULA) approach. Joint Conference of the Asian Council on Ergonomics and Design and the Southeast Asian Network of Ergonomics Societies, 308-316. Springer, Cham.

Yusoff, I. S. M., Sabri, M. F., Wijekoon, R., \& Majid, A. Z. A. (2020). The impact of an economic challenge on health through driving posture among elderly taxi drivers in Malaysia. Journal of Critical Reviews, 7(12), 4177-4184. 